\title{
Dietary intake and nutritional status in patients with systemic sclerosis
}

\author{
A-C Lundberg, A Åkesson, B Åkesson
}

\begin{abstract}
Oesophageal dysmotility and abnormalities of intestinal function are important manifestations in systemic sclerosis and may have a significant effect on nutrient absorption and nutritional status. In this study $\mathbf{3 0}$ patients with systemic sclerosis with symptoms from the gastrointestinal tract were compared with matched healthy control subjects with respect to nutrient intake (four day record), anthropometric measurements, and biochemical nutritional status. The intake of energy (8.1 and 8.4 MJ/day) and its distribution among nutrients did not differ between patients and control subjects, but the lower intake of dietary fibre among patients with systemic sclerosis suggests that they avoided food with a coarse structure, such as coarse bread. The intake of vegetables and fruit also tended to be lower among patients with systemic sclerosis. Half of the patients had a subnormal arm muscle circumference, and two patients also had a subnormal triceps skinfold thickness, indicating severe malnutrition. The concentration of ascorbic acid, $\alpha$-tocopherol, carotene, selenium, and also the proportion of linoleic acid (18:2) in serum phosphatidylcholine was lower in patients than in control subjects.
\end{abstract}

(Ann Rheum Dis 1992; 51: 1143-1148)

Systemic sclerosis often affects the gastrointestinal tract. ${ }^{1}$ Oesophageal dysfunction is present in about $85 \%$ of patients with systemic sclerosis. ${ }^{2}$ Motility disturbances and lower oesophageal sphincter dysfunction are characteristic features and may result in gastrooesophageal reflux, oesophagitis, or stricture. ${ }^{13}$ In the small intestine stasis followed by bacterial overgrowth, or decreased permeability due to intestinal fibrosis, may cause steatorrhea and malabsorption. ${ }^{45}$ These functional derangements in systemic sclerosis may decrease dietary intake and inhibit the digestion and absorption of nutrients, and in a few patients overt malnutrition has been reported. ${ }^{167}$ To obtain more information on the prevalence of nutritional derangements in systemic sclerosis we studied whether patients with systemic sclerosis with reduced oesophageal motility or signs of intestinal disease, or both, had an altered intake of nutrients and foods compared with healthy control subjects. Several anthropometric and biochemical variables of nutritional status were also measured to elucidate whether they were related to the presence of different manifestations of systemic sclerosis or any deviations in dietary intake. The examination was repeated one year after dietary counselling to evaluate possible changes in dietary intake and in biochemical and anthropometric nutritional status.

\section{Subjects and methods}

SUBJECTS

From a group of 72 consecutive patients with systemic sclerosis as defined by the American Rheumatism Association criteria, ${ }^{8} 33$ with pronounced gastrointestinal manifestations were selected. They had decreased oesophageal motility measured by cineradiography or radionuclide transit time, fat malabsorption according to the triolein breath test, or increased bile acid deconjugation. After the dietary survey three patient-control pairs were excluded, and in this work 30 patients with systemic sclerosis were studied, 17 with diffuse scleroderma affecting the arms, legs, and trunk, and 13 with limited cutaneous scleroderma-that is, skin sclerosis limited to the arms and legs. Nine patients were treated with penicillamine (mean $500 \mathrm{mg} /$ day). The control group consisted of one control subject for each patient, matched for sex, age, and place of residence. The controls were randomly selected from the population register and were asked to participate by an invitation letter. The study was approved by the ethics committee of the University of Lund.

\section{CLINICAL ASSESSMENT}

At the time of the study 23 patients had characteristic disorders referable to oesophageal disease including heartburn, regurgitation, and dysphagia, and six vomited at meals. Five patients had intermittent diarrhoea. Skin disease was determined by examination of 24 anatomical sites, ${ }^{4}$ using a $0-3$ scale, with $0=$ normal and $3=$ hidebound skin sclerosis . Pulmonary disease was assessed by function tests to detect restrictive lung disease. ${ }^{4}$

\section{OESOPHAGEAL AND INTESTINAL FUNCTION}

Oesophageal function was assessed by cineradiography using a barium swallow examination in the prone position and by radionuclide transit time of a swallowed bolus of purée in the upright and in the supine position. ${ }^{2}$ Fat malabsorption was assessed by the triolein breath test, and intestinal bacterial overgrowth by the bile acid deconjugation test. ${ }^{9}$

ASSESSMENT OF DIETARY INTAKE

All subjects recorded their ordinary eating
Rheumatology, University Hospital, S-221 85 Lund

Accepted for publication 21 May 1992 
habits at home for four days including a weekend day. A form for keeping four day records was posted to patients and control subjects and they were all instructed by the same dietician (ACL). The subjects were later interviewed about their records by the dietician. The nutrient intake was calculated by a computer program based on the food tables of the Swedish Food Administration. ${ }^{10}$ Mean values from four days were calculated. The intake of some foods, expressed as g/day, was also calculated. Fifteen patients and 16 control subjects took more or less regularly vitamin or mineral supplements, or both. Owing to the irregular intake, the supply of nutrients via supplements was not included in the calculations.

\section{ANTHROPOMETRY}

Anthropometric measurements included weight, height, triceps skinfold, mid-arm circumference, and arm muscle circumference. Triceps skinfold thickness was assessed with a Harpenden calliper. Triceps skinfold thickness and mid-arm circumference were measured half way between the acromion and the olecranon on the non-dominant arm. Mean values from three measurements were calculated. Arm muscle circumference (AMC) was calculated according to the formula: AMC $(\mathrm{cm})=$ MAC $(\mathrm{cm})-0 \cdot 1$ $(\pi \times \mathrm{TSF}(\mathrm{mm}))$, where $\mathrm{MAC}=$ mid arm circumference and $\mathrm{TSF}=$ triceps skinfold. The data were compared with reference values adjusted for sex and age. ${ }^{11}$

\section{BIOCHEMICAL ANALYSIS}

Blood samples were taken from an antecubital vein after the subjects had fasted for 12 hours. Measurements were performed on the day of sampling, or serum samples were stored at $-70^{\circ} \mathrm{C}$ for later analysis. Serum samples were analysed for ascorbic acid, $\alpha$-tocopherol, ${ }^{12}$ carotene,${ }^{13}$ and selenium. ${ }^{14}$ Folate, cobalamine, zinc, and copper determinations, and other biochemical measurements were performed at the department of clinical chemistry, University Hospital of Lund.

To determine the fatty acid composition of serum phosphatidylcholine, lipids were extracted from $1 \mathrm{ml}$ serum by $6 \mathrm{ml}$ methylene chloride:methanol $(1: 1)$ for one hour. After centrifugation the insoluble residue was reextracted with $3 \mathrm{ml}$ of the same solvent mixture. The combined extracts were partitioned with $4 \mathrm{ml} \mathrm{NaCl}(10 \mathrm{~g} / \mathrm{l})$ and the lipid phase was washed twice with $3 \mathrm{ml}$ methanol:water (1:1). After concentration the lipid extract was applied to silica gel thin layer plates which were developed in methylene chloride:methanol: ammonia (60:30:5), containing $5 \mathrm{mg}$ butylated hydroxytoluene as an antioxidant. The phosphatidylcholine spots were visualised by spraying with $0.2 \%$ dichlorofluoroscein in ethanol and transferred to glass tubes for the preparation of fatty acid methyl esters by transesterification. ${ }^{15}$ Fatty acid composition was determined by capillary gas chromatography as described elsewhere. ${ }^{16}$
STATISTICAL METHODS

Differences between patients and control subjects and between different examinations were evaluated by Wilcoxon's signed rank test and the paired $t$ test. For some variables the relation to dysphagia, oesophageal dysmotility, triolein breath test, form of systemic sclerosis, disease duration, sex and age was studied by forward and backward multiple regression analysis.

\section{Results}

CLINICAL EXAMINATION

Table 1 presents some clinical features of the patients. Table 2 gives the presence of gastrointestinal symptoms and disease. Oesophageal motility assessed by cineradiograpy and radionuclide transit time was normal in two patients, slightly decreased in eight, and moderately to severely decreased in 20 . Of the three patients with normal cineradiography, only one had a slightly prolonged radionuclide transit time as seen by oesophageal scintigraphy.

\section{DIETARY INTAKE}

The mean intake of energy did not differ between patients with systemic sclerosis and their control subjects, neither among women nor among men (tables 3 and 4). The contribution of energy from different nutrients was also similar, though the contribution of fat among male patients was marginally lower than in control subjects. The mean intake of total dietary fibre among female and male patients was only $70-80 \%$ of that in control subjects. Among the different fibre fractions, the female patients had a significantly lower intake of pectin, water soluble fibre, cellulose, and

Table 1 Clinical features of patients with systemic sclerosis and control subjects

\begin{tabular}{|c|c|c|}
\hline & $\begin{array}{l}\text { Patients } \\
(n=30)\end{array}$ & $\begin{array}{l}\text { Control } \\
\text { subjects } \\
(n=30)\end{array}$ \\
\hline \multirow{4}{*}{$\begin{array}{l}\text { Mean (range) age (years) } \\
\text { Sex ratio (F:M) } \\
\text { Mean (range) disease } \\
\text { duration (years) } \\
\text { Mean (SD) total skin score } \\
\text { Subnormal vital capacity or } \\
\text { compliance, or both (\%) }\end{array}$} & $\begin{array}{c}48(19-72) \\
1 \cdot 7: 1\end{array}$ & $\begin{array}{c}48(19-72) \\
1 \cdot 7: 1\end{array}$ \\
\hline & $7 \cdot 8(0.5-20)$ & - \\
\hline & $17 \cdot 5(9 \cdot 2)$ & - \\
\hline & 53 & - \\
\hline \multirow{3}{*}{$\begin{array}{l}\text { Mean (range) blood haemo- } \\
\text { globin }(\mathrm{g} / \mathrm{l}) \\
\text { Mean (range) serum } \\
\text { albumin }(\mathrm{g} / \mathrm{l}) \\
\text { Mean (range) serum } \\
\text { creatinine }(\mu \mathrm{mol} / \mathrm{l})\end{array}$} & $121(92-149)$ & $140(119-164)$ \\
\hline & $37(29-43)$ & $37(33-42)$ \\
\hline & $72(44-129)$ & 79 (55-99) \\
\hline
\end{tabular}

${ }^{*}$ Maximum score 72

Table 2 Presence of gastrointestinal symptoms and disease in 30 patients with systemic sclerosis

\begin{tabular}{lcl}
\hline Gastrointestinal manifestations & $\begin{array}{l}\text { No of } \\
\text { patients }\end{array}$ & $\begin{array}{l}\text { Percentage } \\
\text { of patients }\end{array}$ \\
\hline Oesophageal symptoms & & \\
$\quad$ Dysphagia & 20 & 67 \\
Regurgitation & 15 & 50 \\
$\quad$ Vomiting & 6 & 20 \\
Oesophageal dysmotility & 28 & 93 \\
Fat malabsorption & 13 & 43 \\
Increased bile acid deconjugation & 5 & 17
\end{tabular}


Table 3 Daily intake of energy, carbohydrate, fibre, fat, and protein by 19 female patients with systemic sclerosis and their control subjects. Significance of the difference between groups was calculated with the Wilcoxon signed rank test

\begin{tabular}{lccc}
\hline Dietary component & Mean $($ SD) value & & p Value \\
\cline { 2 - 3 } & Patients & Control subjects & \\
\hline Energy (MJ) & $7 \cdot 4(1 \cdot 6)$ & $7 \cdot 9(1 \cdot 4)$ & \\
Carbohydrate (g) & $216(72)$ & $214(38)$ & \\
Carbohydrate (E\%) & $49(9)$ & $46(5)$ & \\
Starch (g) & $46(19)$ & $49(13)$ & \\
Sucrose (g) & $24(14)$ & $22(11)$ & \\
Lactose (g) & $11(8 \cdot 7)$ & $10(10)$ & \\
Monosaccharides (g) & $22(14)$ & $24(8 \cdot 3)$ & $<0 \cdot 05$ \\
Fibre (g) & $10 \cdot 2(4 \cdot 0)$ & $12 \cdot 8(2 \cdot 7)$ & $<0 \cdot 02$ \\
Pectin (g) & $0 \cdot 8(0 \cdot 7)$ & $1 \cdot 2(0 \cdot 6)$ & \\
Water soluble fibre (g) & $1 \cdot 5(0 \cdot 7)$ & $2 \cdot 0(0 \cdot 9)$ & \\
Water insoluble fibre (g) & $1 \cdot 9(0 \cdot 8)$ & $2 \cdot 2(1 \cdot 0)$ & $<0 \cdot 05$ \\
Non-cellulose polysaccharide (g) & $3 \cdot 4(1 \cdot 4)$ & $4 \cdot 2(1 \cdot 9)$ & \\
Cellulose (g) & $1 \cdot 4(0 \cdot 7)$ & $1 \cdot 9(0 \cdot 8)$ & \\
Lignin (g) & $0 \cdot 5(0 \cdot 3)$ & $0 \cdot 7(0 \cdot 3)$ & \\
Fat (g) & $74(19)$ & $81(20)$ & \\
Fat (E) & $37(9)$ & $38(5)$ & \\
Saturated fat (g) & $30(9 \cdot 2)$ & $33(7.4)$ & \\
Monounsaturated fat (g) & $24(7 \cdot 2)$ & $26(7 \cdot 3)$ & \\
Polyunsaturated fat (g) & $9 \cdot 2(2 \cdot 8)$ & $10(2 \cdot 9)$ & \\
P/St ratio & $0 \cdot 33(0 \cdot 12)$ & $0 \cdot 30(0 \cdot 06)$ & \\
Protein (g) & $58(10)$ & $68(13)$ & 0.02 \\
Protein (E\%) & $13(2)$ & $15(3)$ & \\
\hline
\end{tabular}

* Sum of water soluble and water insoluble fibre.

$+\mathrm{P} / \mathrm{S}=$ polyunsaturated fat/saturated fat.

Table 4 Daily intake of energy, carbohydrate, fibre, fat, and protein by 11 male patients with systemic sclerosis and their control subjects. Significance of the difference between groups was calculated with the Wilcoxon signed rank test

\begin{tabular}{|c|c|c|c|}
\hline \multirow[t]{2}{*}{ Dietary component } & \multicolumn{2}{|c|}{ Mean (SD) value } & \multirow[t]{2}{*}{ p Value } \\
\hline & Patients & Control subjects & \\
\hline $\begin{array}{l}\text { Energy (MJ) } \\
\text { Carbohydrate (g) } \\
\text { Carbohydrate (E\%) } \\
\text { Starch (g) } \\
\text { Sucrose (g) } \\
\text { Lactose (g) } \\
\text { Monosaccharides (g) }\end{array}$ & $\begin{aligned} 9 \cdot 0(1 \cdot 8) \\
235(60) \\
44(4) \\
77(24) \\
12(8 \cdot 0) \\
16(5) \\
13(7 \cdot 5)\end{aligned}$ & $\begin{aligned} 9 \cdot 2(1 \cdot 9) \\
259(54) \\
48(6) \\
75(32) \\
23(12) \\
13(9 \cdot 3) \\
26(7 \cdot 8)\end{aligned}$ & $\begin{array}{r}<0.05 \\
0.01\end{array}$ \\
\hline $\begin{array}{l}\text { Fibre }(\mathrm{g}) \\
\text { Pectin }(\mathrm{g}) \\
\text { Water soluble fibre }(\mathrm{g}) \\
\text { Water insoluble fibre }(\mathrm{g}) \\
\text { Non-cellulose polysaccharide }(\mathrm{g})^{*} \\
\text { Cellulose }(\mathrm{g}) \\
\text { Lignin }(\mathrm{g})\end{array}$ & $\begin{array}{l}10.5(2.9) \\
0.6(0.3) \\
1.6(0.7) \\
2.5(1.4) \\
4.0(2.0) \\
1.3(0.6) \\
0.6(0.3)\end{array}$ & $\begin{aligned} 15.0(3.3) \\
0.9(0.4) \\
2.0(1 \cdot 1) \\
2.7(1 \cdot 8) \\
4.7(2 \cdot 8) \\
2.0(0.7) \\
0.8(0.3)\end{aligned}$ & $<0.02$ \\
\hline $\begin{array}{l}\text { Fat (g) } \\
\text { Fat (E\%) } \\
\text { Saturated fat (g) } \\
\text { Monounsaturated fat (g) } \\
\text { Polyunsaturated fat (g) } \\
\text { P/S† ratio }\end{array}$ & $\begin{array}{l}94(19) \\
39(4) \\
39(12) \\
28(4 \cdot 7) \\
10(2 \cdot 5) \\
0 \cdot 29(0 \cdot 12)\end{array}$ & $\begin{array}{l}89(26) \\
36(6) \\
35(11) \\
28(8 \cdot 6) \\
12(4 \cdot 1) \\
0 \cdot 34(0 \cdot 07)\end{array}$ & 0.05 \\
\hline $\begin{array}{l}\text { Protein (g) } \\
\text { Protein (E\%) }\end{array}$ & $\begin{array}{l}82(18) \\
15(2)\end{array}$ & $\begin{array}{l}73(18) \\
13(2)\end{array}$ & $<0.01$ \\
\hline
\end{tabular}

${ }^{*}$ Sum of water soluble and water insoluble fibre.

$+\mathrm{P} / \mathrm{S}=$ polyunsaturated fat/saturated fat.

Table 5 Daily intake of micronutrients by female and male patients with systemic sclerosis and their control subjects. Significance of the difference between groups was calculated by Wilcoxon's signed rank test

\begin{tabular}{|c|c|c|c|c|c|}
\hline \multirow[t]{2}{*}{ Dietary component } & \multicolumn{2}{|c|}{$\begin{array}{l}\text { Mean }(S D) \text { values for } \\
\text { women }(n=19)\end{array}$} & \multirow[t]{2}{*}{ p Value } & \multicolumn{2}{|c|}{$\begin{array}{l}\text { Mean }(S D) \text { values for } \\
\text { men }(n=11)\end{array}$} \\
\hline & Patients & $\begin{array}{l}\text { Control } \\
\text { subjects }\end{array}$ & & Patients & $\begin{array}{l}\text { Control } \\
\text { subjects }\end{array}$ \\
\hline $\begin{array}{l}\text { Retinol (mg) } \\
\text { Carotene (mg) } \\
\alpha \text {-Tocopherol (mg) } \\
\text { Folate (mg) } \\
\text { Vitamin B-12 ( } \mu \mathrm{g}) \\
\text { Ascorbic acid (mg) } \\
\text { Calcium (g) } \\
\text { Phosphorus (g) } \\
\text { Magnesium (g) } \\
\text { Iron (mg) } \\
\text { Zinc (mg) } \\
\text { Copper (mg) } \\
\text { Selenium ( } \mathrm{gg})\end{array}$ & $\begin{array}{c}1 \cdot 0(0 \cdot 6) \\
2 \cdot 5(4 \cdot 6) \\
5 \cdot 8(2 \cdot 5) \\
0 \cdot 10(0 \cdot 06) \\
4 \cdot 3(2 \cdot 3) \\
65(62) \\
0 \cdot 78(0 \cdot 24) \\
1 \cdot 0(0 \cdot 21) \\
0 \cdot 18(0 \cdot 05) \\
12(4) \\
6 \cdot 3(1 \cdot 5) \\
0 \cdot 39(0 \cdot 22) \\
17(7)\end{array}$ & $\begin{array}{l}1 \cdot 5(1 \cdot 9) \\
2 \cdot 4(2 \cdot 1) \\
6 \cdot 3(2 \cdot 4) \\
0 \cdot 12(0 \cdot 05) \\
8 \cdot 4(14) \\
77(42) \\
0 \cdot 90(0 \cdot 33) \\
1 \cdot 2(0 \cdot 27) \\
0 \cdot 22(0 \cdot 04) \\
13(3) \\
8 \cdot 2(1 \cdot 6) \\
0 \cdot 70(0 \cdot 76) \\
18(7)\end{array}$ & $\begin{array}{l}<0 \cdot 01 \\
<0.05\end{array}$ & $\begin{array}{c}1 \cdot 6(2 \cdot 5) \\
2 \cdot 3(2 \cdot 4) \\
6 \cdot 0(1 \cdot 5) \\
0 \cdot 11(0 \cdot 03) \\
5 \cdot 1(2 \cdot 0) \\
56(31) \\
1 \cdot 0(0 \cdot 37) \\
1.4(0 \cdot 38) \\
0 \cdot 23(0 \cdot 04) \\
14(4) \\
9 \cdot 2(1 \cdot 5) \\
0 \cdot 41(0 \cdot 13) \\
26(18)\end{array}$ & $\begin{array}{c}1 \cdot 0(0 \cdot 8) \\
1 \cdot 8(1 \cdot 2) \\
5 \cdot 8(1 \cdot 3) \\
0 \cdot 11(0 \cdot 03) \\
4 \cdot 3(2 \cdot 2) \\
69(36) \\
0 \cdot 86(0 \cdot 21) \\
1 \cdot 2(0 \cdot 29) \\
0 \cdot 23(0 \cdot 06) \\
15(4) \\
8.9(2 \cdot 2) \\
0 \cdot 52(0 \cdot 19) \\
21(20)\end{array}$ \\
\hline
\end{tabular}

lignin; male patients of cellutose only. To elucidate this point further, the intake of a few food groups rich in fibre was calculated. The median intake of coarse bread was 23 and $37 \mathrm{~g} /$ day $(\mathrm{p}<0.01)$ in patients and control subjects respectively. The differences between intakes of vegetables, 63 and $89 \mathrm{~g} / \mathrm{day}$, and of fruit, 65 and $101 \mathrm{~g} /$ day, respectively were not statistically significant because of the wide spread of results. The patients' intake of other major carbohydrates did not differ from that of control subjects except for a lower intake of sucrose and monosaccharides among male patients.

The intake of total fat, saturated, monounsaturated, and polyunsaturated fat did not differ significantly between patients and control subjects (tables 3 and 4). Neither was the intake of vitamins different in the two groups, whereas the intake of zinc, copper, and magnesium was lower in female patients compared with control subjects (table 5).

\section{ANTHROPOMETRY}

As might be expected body weight and body mass index tended to be lower in male patients than in control subjects, but among women the opposite finding was noted for unknown reasons (figure). Moreover the mean triceps skinfold thickness was significantly higher in female patients compared with control subjects, but male patients also tended to have a higher triceps skinfold thickness. Three female patients and three female control subjects had triceps skinfold values below the fifth centile. Arm muscle circumference was significantly lower in female and male patients compared with control subjects. Seven female and seven male patients but only one female control subject had an arm muscle circumference below the fifth centile. Owing to the mode of calculation, the lower arm muscle circumference in patients may to some extent reflect a high triceps skinfold thickness, but it is not known to what extent the increased skin thickness in systemic sclerosis causes a falsely high triceps skinfold value. ${ }^{7}$ In two female patients the triceps skinfold thickness and arm muscle circumference were below the fifth centile suggesting significant energy malnutrition (table 6).

Table 6 Clinical features and nutritional parameters in two female patients with malnutrition (triceps skinfold thickness and arm muscle circumference below the fifth centile)

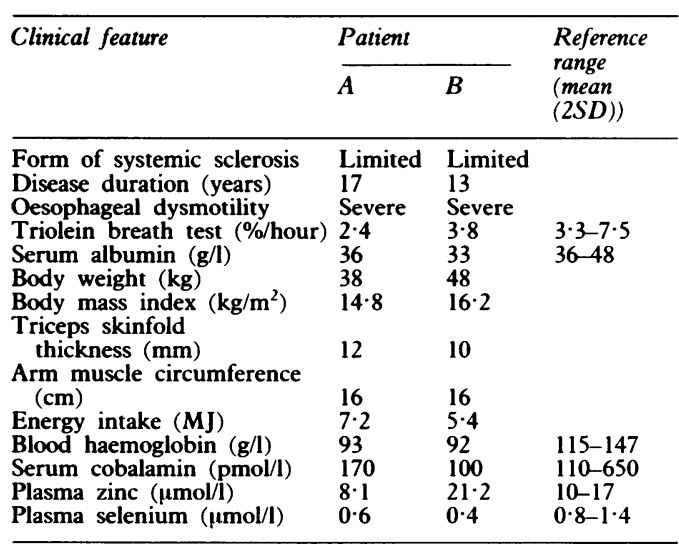



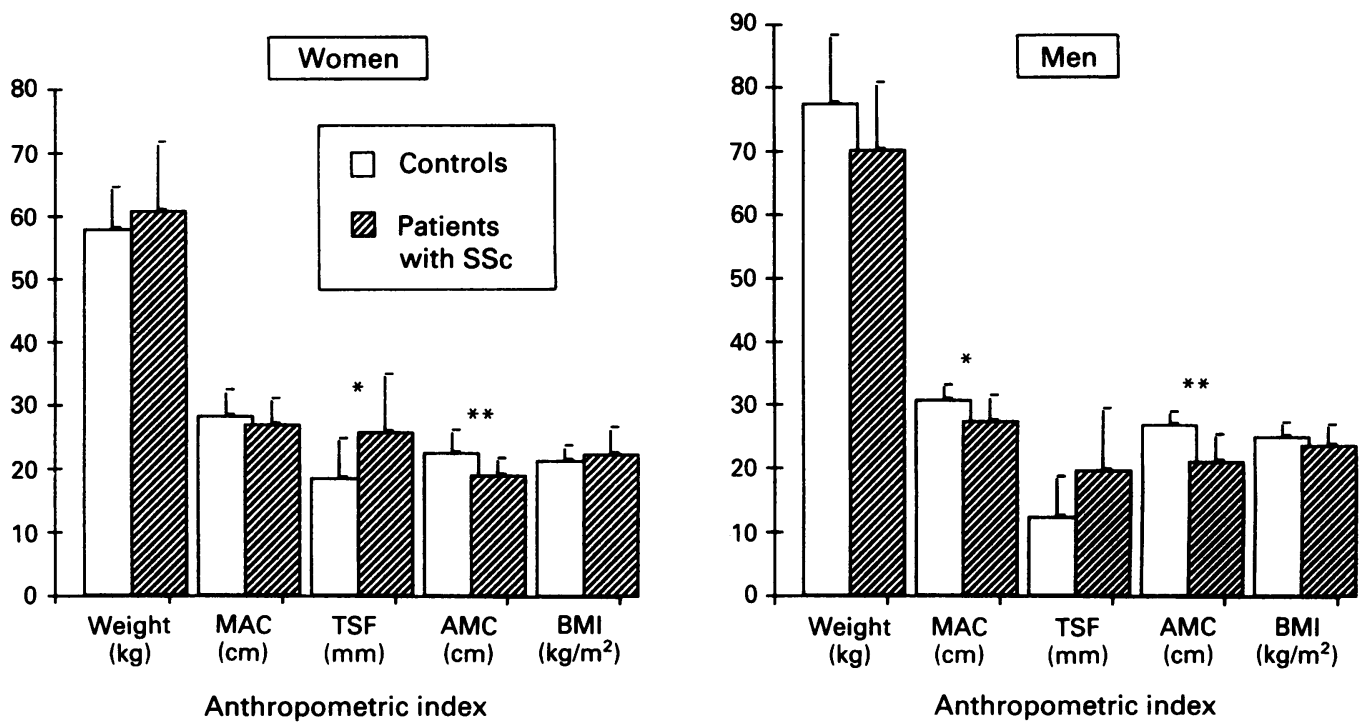

Anthropometry of patients with systemic sclerosis $(S S c) . M A C=$ mid arm circumference; $T S F=$ triceps skinfold thickness; $A M C=$ arm muscle circumference; $B M I=$ body mass index. Mean $(S D)$ values are shown. " $p<0 \cdot 05 ;$ * " $p<0 \cdot 01$.

BIOCHEMICAL NUTRITIONAL STATUS

The concentration of ascorbic acid, $\alpha$-tocopherol, carotene, and selenium in serum samples was significantly lower in patients than in control subjects (table 7). The fatty acid composition of serum phosphatidylcholine was also significantly different in patients with a lower proportion of linoleic acid (18:2) and total n-6 fatty acids and a higher proportion of dihomo- $\gamma$-linoleic acid $(20: 3, n-6)$ (table 8$)$.

Table 7 Concentration of nutrients in serum of patients with systemic sclerosis and their control subjects

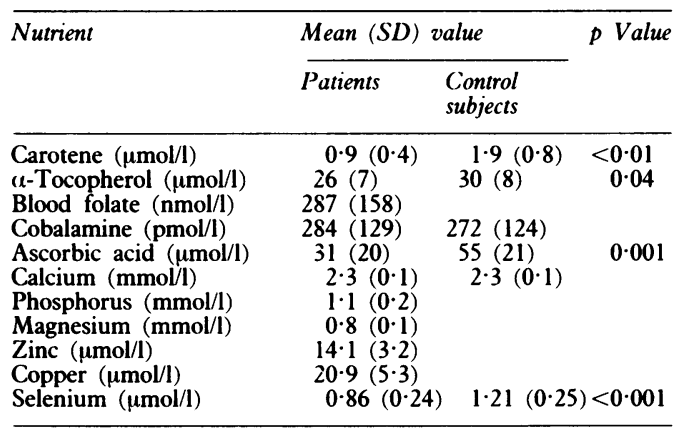

Table 8 Fatty acid composition in serum phosphatidylcholine of patients with systemic sclerosis and their control subjects (percentage of total fatty acids)

\begin{tabular}{|c|c|c|c|}
\hline \multirow[t]{2}{*}{ Fatty acid ${ }^{*}$} & \multicolumn{2}{|c|}{ Mean (SD) value } & \multirow[t]{2}{*}{ p Value } \\
\hline & Patients & $\begin{array}{l}\text { Control } \\
\text { subjects }\end{array}$ & \\
\hline 14:0 & $0.53(0.27)$ & $0.51(0.23)$ & \\
\hline 16:0 & $32 \cdot 23(1 \cdot 78)$ & $31.81(1.51)$ & \\
\hline $16: 1$ & $0.73(0.32)$ & $0.62(0.31)$ & \\
\hline $18: 0$ & $12 \cdot 35(1 \cdot 56)$ & $12.87(1.19)$ & \\
\hline $18: 1$ & $12.73(1.47)$ & $12.05(1.68)$ & \\
\hline $18: 2$ & $23.74(2.95)$ & $25.56(2.42)$ & 0.02 \\
\hline $18: 3(n-3)$ & $0.20(0.13)$ & $0.21(0.07)$ & \\
\hline $20: 3(n-6)$ & $2.57(0.70)$ & $2 \cdot 19(0.54)$ & 0.02 \\
\hline $20: 4(n-6)$ & $7 \cdot 74(1 \cdot 32)$ & $7 \cdot 64(1 \cdot 26)$ & \\
\hline $20: 5(n-3)$ & $1.22(0.54)$ & $1.48(0.79)$ & \\
\hline $22: 5(n-3)$ & $0.80(0.26)$ & $0.70(0.16)$ & \\
\hline $22: 6(n-3)$ & $5 \cdot 16(1 \cdot 71)$ & $4 \cdot 70(1 \cdot 18)$ & \\
\hline Total n-6 & $34.06(2.57)$ & $35 \cdot 08(2 \cdot 25)$ & 0.03 \\
\hline Total n-3 & $7 \cdot 39(2 \cdot 27)$ & $7.09(1.77)$ & \\
\hline Total saturated & $45 \cdot 10(1 \cdot 18)$ & $45 \cdot 17(0 \cdot 98)$ & \\
\hline $18: 2 / 20: 4$ & $3.19(0.84)$ & $3.40(0.68)$ & \\
\hline $20: 3 / 20: 4$ & $0 \cdot 34(0 \cdot 10)$ & $0.29(0.07)$ & 0.01 \\
\hline $20: 5 / 20: 4$ & $0 \cdot 17(0.08)$ & $0.20(0.13)$ & \\
\hline
\end{tabular}

Fatty acids are abbreviated by number of carbon atoms: number of double bonds followed by categorisation to fatty acid families n-6 or n-3.
No significant differences were observed for saturated and monounsaturated fatty acids and for fatty acids in the $n-3$ series.

\section{NUTRITIONAL VARIABLES IN RELATION TO} CLINICAL SYMPTOMATOLOGY

Nutrient intake and biochemical nutritional status were compared in different subgroups of patients. Among the 15 patients who reported regular regurgitation compared with the 15 who did not the intake of carotene, copper, pectin, water soluble fibre, cellulose, and lignin was significantly higher, which was also seen in the corresponding subgroups of women. No differences in biochemical nutritional status were observed. The only differences between the 20 patients with dysphagia and the 10 without were lower intakes of total fat, polyunsaturated fat, and $\alpha$ tocopherol in the latter group, but this may be explained by its lower proportion of male patients. Compared with patients with slightly disturbed oesophageal motility, those with severe disturbance had a significantly lower intake of carotene $(p=0.01)$ and pectin $(\mathrm{p}=0.03)$, but no significantly different biochemical nutritional status. Compared with patients with a subnormal value in the triolein breath test, those with normal values had a significantly higher proportion of arachidonic acid in serum phosphatidylcholine, but no difference in serum concentrations of micronutrients. The nutritional status of patients with diffuse or limited systemic sclerosis did not differ significantly except for a lower plasma copper concentration in the former group $(p=0.04)$. No relation of penicillamine treatment to nutritional status was found.

By multiple regression analysis triceps skinfold thickness was found to be lower in patients with dysphagia and in patients with limited systemic sclerosis. In contrast arm muscle circumference was higher in patients with dysphagia and also in patients with a short duration of disease and a high value in the triolein breath test.

In two patients nutritional parameters indicated severe energy malnutrition with the values 
of triceps skinfold thickness and arm muscle circumference being below the fifth centile of healthy subjects (table 6). These patients had severe dysphagia, long disease duration, anaemia, subnormal body mass index, and subnormal values of several micronutrients in blood. The two patients had later to be treated with enteral or parenteral nutrition due to oesophageal stricture plus intestinal stasis and severe diarrhoea respectively, and they died due to several complications within three years.

\section{EFFECT OF DIETARY COUNSELLING}

Based on the data from the interview and the first four day record, dietary advice was given to the patients and then the investigation was repeated after one year. Patients with a low consumption of vegetables and fruit were recommended to eat more foods rich in vitamin C. When the intake of meat was low, an increased intake of products rich in iron was recommended. Energy supplements were recommended in severe dysphagia. After one year the dietary intake of macronutrients and fibre was essentially unchanged; the approximately $50 \%$ increased intake of pectin may reflect an increased consumption of vegetables and fruit. This may also explain the increased intake of carotene, ascorbic acid, and magnesium $(16-30 \%)$ at the second investigation. There was, however, no change in the concentration of micronutrients in blood, or in the anthropometric indices.

\section{Discussion}

Although a few reports on the use of parenteral nutrition in patients with systemic sclerosis with severe intestinal disease have been published, ${ }^{6} 7^{17-19}$ this study is the first to deal with dietary intake and nutritional status in a larger group of patients with systemic sclerosis characterised as described previously. ${ }^{4}$ This type of data should give information on the nutritional deficiencies that are most likely to develop in patients with systemic sclerosis and on suitable methods to determine decreased nutrient storage, and also provide guidance on how to optimise nutritional treatment.

The natural history of systemic sclerosis is difficult to predict for the individual patient. In some patients rapid progression results in death secondary to pulmonary, cardiac, or renal failure, ${ }^{20}$ and in others the disease is relatively stable for long periods of time, though the gastrointestinal disease usually proceeds. ${ }^{21}$ In the latter group nutritional support may play an important part.

The multiple gastrointestinal manifestations in systemic sclerosis can affect the nutritional status of patients by several mechanisms. Perioral skin sclerosis and oesophageal dysmotility and stricture may limit the intake of the total volume of foods and especially of foods that are bulky and difficult to disintegrate by chewing. We found the intake of energy and macronutrients to be similar in patients and their control subjects, and the main significant difference in patients was a lower intake of dietary fibre, to some extent consumed as coarse bread, vegetables, and fruit, which is consistent with this hypothesis.

The decreased intestinal function in systemic sclerosis with dysmotility, decreased pancreatic function, bacterial overgrowth, and malabsorption of fat, bile acids, and other compounds $^{122-24}$ may lead to decreased nutrient uptake and increased nutrient losses. Hence in spite of the similar energy intake in patients and control subjects, arm muscle circumference was lower among our patients, and two patients had a triceps skinfold thickness and arm muscle circumference below the fifth centile, suggesting that decreased nutrient absorption or increased losses, or both, were responsible for these effects.

The triolein breath test indicated that $43 \%$ of the patients with systemic sclerosis had fat malabsorption, which may also explain the decreased proportion of linoleic acid in serum phosphatidylcholine. This decrease was less than that observed in patients who had undergone ileal resection and were studied with the same methods. ${ }^{25}$ No abnormality was observed in the proportions of $n-3$ polyunsaturated fatty acids, which have been suggested as a therapeutic agent after peroral administration. ${ }^{26}$

No difference in the intake of vitamins was observed between patients and control subjects, and only a slightly lower intake of some minerals and trace elements was found among female patients. There was no indication that this increased the risk of trace element deficiency as plasma concentrations of the same elements were in the normal range, except for selenium. For selenium the intake in patients and control subjects was calculated to be similar, and the decreased plasma values may be due to decreased absorption or to disease activity. ${ }^{27}$ An extreme case of copper deficiency in a patient with systemic sclerosis has been reported, ${ }^{6}$ but most studies have described normal or only slightly subnormal trace element concentrations in plasma. ${ }^{79}$ Treatment with penicillamine did not affect the concentration of zinc in plasma, but lowered that in granulocytes. ${ }^{28}$ With respect to vitamins, the patients had lower concentrations of $\alpha$-tocopherol, carotene, and ascorbic acid, which for the first two compounds is probably explained by a decreased fat absorption. In contrast no decrease in the concentration of retinol and vitamin D metabolites in patients with systemic sclerosis was reported. ${ }^{929}$ The concentration of ascorbic acid is not usually decreased in patients with gastrointestinal disease, ${ }^{25} 30$ and its lower value is probably not explained by decreased absorption. Instead it may be due to decreased consumption of fruit rich in ascorbic acid, reported by several patients, or reflect a consumption of ascorbic acid in the body due to inflammatory processes. ${ }^{31} 32$

We also investigated the effects of dietary advice in patients with systemic sclerosis with emphasis on an increased intake of foods which may improve iron and ascorbic acid intake. No changes in biochemical and anthropometric variables were observed after one year, though the reported mean intake of carotene, ascorbic 
acid, magnesium, and copper increased. Maybe these changes were too small to affect nutritional status; alternatively, the patients may have reported but not effected the prescribed dietary changes. At present it is not possible to decide whether this type of dietary advice had any beneficial effects. In a few studies of patients with systemic sclerosis and advanced bowel disease, treatment with enteral or parenteral nutrition resulted in weight gain and also increased triceps skinfold thickness in a sizeable proportion of the patients, ${ }^{7} 18$ but the overall prognosis in this group of patients with advanced systemic sclerosis is poor in spite of active nutritional support. ${ }^{18} 19$

Although nutritional support may not alter the natural history of systemic sclerosis, progressive debilitation due to nutritional depletion can be avoided. ${ }^{12}$ In particular, in patients with severe dysphagia, diarrhoea, or weight loss, the need for nutritional support should be routinely evaluated. The present study indicates that measurement of anthropometric indices and the concentrations of fat soluble vitamins in plasma are useful markers for this purpose.

Ms B Mărtensson, B. Ekström and B. Mattsson performed the chemical analyses of nutrients. Dr T Möller, Center of Oncology, University of Lund, provided data on matched control subjects from the population register. The study was supported by grants from the Malmöhus County Council, the Swedish Council for Planning and Coordination of Research, the Kock Foundation, Planning and Coordination of Research, the Kock Foundation,
the Påhlsson Foundation and the Swedish Medical Research Council (project no. 3968).
Cong

1 Cohen S, Lanfer I, Snape W J, Shian Y F, Levine G M, Jimenez $S$. The gastrointestinal manifestations of scleroderma: pathogenesis and management. Gastroenterology 1980; 79: $155-66$.

2 Åkesson A, Gustafsson T, Wollheim F, Brismar J. Esophageal dysfunction and radionuclide transit in progressive
systemic sclerosis. Scand $\mathcal{J}$ Rheumatol 1987; 16: 291-9. 3 Merlo A, Cohen S. Swallowing disorders. Ann Rev Med 1988; 39: 17-28.

4 Åkesson A, Wollheim F A. Organ manifestations in 100 patients with progressive systemic sclerosis. A comparison between the CREST syndrome and diffuse scleroderma. Br 7 Rheumatol 1989; 28: 281-6.

5 King C E, Toskes P P. Small intestinal bacterial overgrowth. Gastroenterology 1979; 76: 1035-55.

6 Vilter R W, Bozian R C, Hess E V, Zellner D C, Petering H G. Manifestations of copper deficiency in a patient with systemic sclerosis on intravenous hyperalimentation. $N$ Engl f Med 1974; 291: 188-91.

7 Grabowski G, Grant J P. Nutritional support in patients with systemic scleroderma. $\mathcal{F}$ Parenter Enteral Nutr 1989; 13: systemic
$147-51$.

8 Masi A T, Rodnan G P, Medsger T A, et al. Preliminary criteria for the classification of systemic sclerosis (scleroderma). Arthritis Rheum 1980; 23: 581-90.

9 Åkesson A, Åkesson B, Gustafson T, Wollheim F. Gastrointestinal function in patients with progressive systemic sclerosis. Clin Rheumatol 1985; 4: 441-8.
10 Livsmedelstabeller. Sweden: National Food Administration, 1986

11 Symreng T. Arm anthropometry in a large reference population and in surgical patients. Clinical Nutrition 1982; 1 211-9.

12 Johansson U, Portinsson S, Åkesson A, Svantesson $H$ Ockerman P A, Ákesson B. Nutritional status in girls with uvenile chronic arthritis. Human Nutrition; Clinical Nutrition 1986; 40C: 57-67.

13 Matthews-Roth M M, Stampfer M J. Some factors affecting determination of carotenoids in serum. Clin Chem 1984; 30: 459-61.

14 Borglund $\mathrm{M}$, Åkesson A, Åkesson B. Distribution of selenium and glutathione peroxidase in plasma, compared in healthy subjects and rheumatoid arthritis patients. Scand 7 Clin Lab Invest 1988; 48: 27-32.

15 Ekström B, Nilsson $\AA$, Åkesson B. Lipolysis of polyenoic fatty acid esters of human chylomicrons by lipoprotein lipase. Eur $\mathcal{F}$ Clin Invest 1989; 19: 259-64.

16 Johansson U, Portinsson S, Åkesson A, Svantesson H, Âkesson B. Fatty acid composition of plasma phosphatidylcholine and erythrocyte lipids, and dietary fat intake in juvenile chronic arthritis. Prog Lipid Res 1986; 25: 579-82.

17 Stafford-Brady F J, Kahn H J, Ross T M, Russell M L. Advanced scleroderma bowel: complications and management. I R heumatol 1988; 15: 869-74.

18 Swee Cheng Ng, Clements P J, Berquist W E, Furst D E Paulus H E. Home central venous hyperalimentation in fifteen patients with severe scleroderma bowel disease. Arthritis Rheum 1989; 32: 212-6.

19 Stokes M A, Irving M H. Mortality in patients on home parenteral nutrition. F Parenter Enteral Nutr 1989; 13: 172-5.

20 Altman R D, Medsger Jr T A, Bloch D A, Michel B A. Predictors of survival in systemic sclerosis (scleroderma). Arthritis Rheum 1991; 34: 403-13.

21 Henchl L, Stentoft P, Aggestrup S. The progress of oesophageal involvement in progressive systemic sclerosis during D-penicillamine treatment. Scand F Rheumatol 1989 18: 149-55

22 Poirier T J, Rankin G B. Gastrointestinal manifestations of progressive systemic scleroderma based on a review of 364 cases. Am f Gastroenterol 1972; 54: 30-44.

23 Hendel L, Worning $H$. Exocrine pancreatic function in patients with progressive systemic sclerosis. Scand F Gastroenterol 1989; 24: 461-6.

24 Pazzi P, Putinati S, Bagni B, Govoni M, Trotta F. Bile acid malabsorption in progressive systemic sclerosis. Gut 1988; 29: $552-3$.

$25 \AA$ kesson B, Nilsson $\AA$. Intestinal absorption of phosphatidyl choline and triglyceride after ileal resection. Scand $\mathcal{f}$ Gastroenterol 1988; 23: 251-6.

26 DiGiacomo R A, Kremer J M, Shah D M. Fish-oil dietary supplementation in patients with Raynaud's phenomenon: double-blind, controlled, prospective study. $A m \mathcal{F} M e d$ 1989; 86: 158-64.

27 Åkesson B. Plasma selenium in patients with abnorma plasma protein patterns. Trace Elements in Medicine 1987; 4 77-9.

28 Jepsen L V, Eggert J. Zinc and zinc-dependent enzymes in penicillamine-treated patients with generalized scleroderma. Acta Derm Venereol (Stockh) 1984; 64: 424-7.

29 Serup J, Hagdrup H. Vitamin D metabolites in generalized scleroderma. Acta Derm Venereol (Stockh) 1985; 65: 343-5.

30 Staël von Holstein C, Ibrahimbegovic E, Walther B, Ákesson B. Nutrient intake and biochemical markers of nutritional s. Nutrient intake and biochemical markers of nutritional status during long-term follow-up after total and

31 Hemilä $\mathbf{H}$, Roberts $\mathrm{P}$, Wikström M. Activated polymorphonuclear leucocytes consume vitamin C. FEBS Lett 1984; 178: $25-30$.

32 Jacobsson L, Lindgärde F, Manthorpe R, Åkesson B Correlation of fatty acid composition of adipose tissue lipids and serum phosphatidylcholine and serum concentrations of micronutrients with disease duration in rheumatoid arthritis. Ann Rheum Dis 1990; 49: 901-5. 